\title{
Factor structure of the University Personality Inventory in Japanese medical students
}

\author{
Norio Sugawara ${ }^{12^{*}}$ D , Norio Yasui-Furukori ${ }^{2}$, Masayuki Sayama ${ }^{1}$ and Kazutaka Shimoda ${ }^{2}$
}

\begin{abstract}
Background: The age of onset for most mental disorders is typically young adulthood, and the university setting is an important one for addressing mental health. The University Personality Inventory (UPI), which was developed to detect mental health problems in university students, is widely used for screening in Japan. However, there have been limited reports on the factor structure of the UPI based on a statistical test for binary indicators. The objective of this study was to assess the factor structure of the UPI in Japanese medical students.

Methods: This study examined the factor structure of the UPI in a sample of 1185 Japanese medical students at the time of university admission. The students were divided into subgroup A $(n=589)$ and subgroup B $(n=596)$ according to their year of university admission. Based on tetrachoric correlation coefficients, exploratory factor analysis (EFA) with promax rotation was applied to explore the dimensions of the inventory in subgroup $A$. Confirmatory factor analysis (CFA) was then conducted to verify the dimensions in subgroup B.
\end{abstract}

Results: The EFA with categorical variables yielded four factors in subgroup A. These factors, accounting for 48.9\% of the variance, were labeled "Depression and Irritability", "Anxiety and Persecutory Belief", "Physical Symptoms", and "Dependence". The new four-factor structure showed good fit, and traditional factor structures previously reported were replicated via CFA. The internal consistency reliability was good for the overall UPI scale $(a l p h a=0.97)$ and for its four new factors (alpha $=0.83-0.91$ ).

Conclusions: The UPI is a valid and reliable measure that can be used to assess symptoms across four dimensions of mental health in university settings. These findings offer a starting point for the detection of individuals with mental health problems.

Keywords: University personality inventory, Medical students, Exploratory factor analysis, Confirmatory factor analysis

\section{Background}

The age of onset for most mental disorders is typically young adulthood [1]. In Japan, more than half of young adults receive postsecondary education [2], and universities are an important setting for addressing mental

\footnotetext{
* Correspondence: nsuga3@dokkyomed.ac.jp

${ }^{1}$ Health Services Center for Students and Staff, Dokkyo Medical University, 880 Kitakobayashi, Mibu, Tochigi 321-0293, Japan

${ }^{2}$ Department of Psychiatry, Dokkyo Medical University School of Medicine, 880 Kitakobayashi, Mibu, Tochigi 321-0293, Japan
}

health. Approximately half of university students are living away from home for the first time and face academic pressure as they study for a degree [3]. Surveys of student life indicate that in addition to academic pressure, university students encounter a multitude of stressors related to financial strains, career choice, and friendship [3]. Compared to the general population, university students might have poorer health-related quality of life [4], and their mental health is more of a problem than their

(c) The Author(s). 2020 Open Access This article is licensed under a Creative Commons Attribution 4.0 International License, which permits use, sharing, adaptation, distribution and reproduction in any medium or format, as long as you give appropriate credit to the original author(s) and the source, provide a link to the Creative Commons licence, and indicate if changes were made. The images or other third party material in this article are included in the article's Creative Commons licence, unless indicated otherwise in a credit line to the material. If material is not included in the article's Creative Commons licence and your intended use is not permitted by statutory regulation or exceeds the permitted use, you will need to obtain permission directly from the copyright holder. To view a copy of this licence, visit http://creativecommons.org/licenses/by/4.0/. The Creative Commons Public Domain Dedication waiver (http://creativecommons.org/publicdomain/zero/1.0/) applies to the data made available in this article, unless otherwise stated in a credit line to the data. 
Table 1 Factor loadings in the exploratory factor analysis of the university personality inventory

\begin{tabular}{|c|c|c|c|c|c|}
\hline Item & & Factor 1 & Factor 2 & Factor 3 & Factor 4 \\
\hline 1 & Poor appetite & 0.016 & -0.056 & 0.664 & 0.106 \\
\hline 2 & Feel sick, stomachache & 0.003 & 0.013 & 0.761 & 0.019 \\
\hline 3 & Easily have diarrhea or constipation & -0.145 & 0.183 & 0.388 & 0.139 \\
\hline 4 & Care about palpitation and pulse & -0.129 & 0.393 & 0.404 & 0.018 \\
\hline 6 & Full of dissatisfaction and complaints & 0.693 & 0.145 & -0.011 & 0.013 \\
\hline 7 & High expectation from parents & 0.483 & 0.038 & 0.039 & -0.126 \\
\hline 8 & My past and family is misfortune & 0.766 & 0.050 & -0.183 & -0.154 \\
\hline 9 & Over-worry about my future & 0.177 & 0.214 & -0.059 & 0.406 \\
\hline 10 & Do not like meeting others & 0.584 & -0.006 & 0.200 & 0.083 \\
\hline 11 & Feel that I am not myself & 0.285 & 0.238 & 0.068 & 0.349 \\
\hline 12 & Lack of enthusiasm and positivity & 0.470 & -0.271 & 0.538 & 0.184 \\
\hline 13 & Pessimistic & 0.358 & 0.152 & 0.185 & 0.282 \\
\hline 14 & Distracted & 0.164 & 0.119 & 0.224 & 0.405 \\
\hline 15 & Over-uneven in emotion & 0.430 & 0.264 & 0.042 & 0.110 \\
\hline 16 & Frequent insomnia & 0.245 & 0.072 & 0.230 & 0.021 \\
\hline 17 & Headache & 0.098 & -0.018 & 0.691 & -0.076 \\
\hline 18 & Ache in neck and shoulder & -0.043 & -0.001 & 0.632 & -0.096 \\
\hline 19 & Chest pain or feel oppressed & 0.040 & 0.132 & 0.545 & 0.050 \\
\hline 21 & Intolerance & 0.048 & 0.409 & -0.255 & 0.576 \\
\hline 22 & Inclined to worry & 0.234 & 0.291 & 0.126 & 0.235 \\
\hline 23 & Restless & 0.522 & 0.327 & 0.033 & -0.061 \\
\hline 24 & Irritable & 0.657 & 0.329 & -0.074 & -0.112 \\
\hline 25 & Have idea of wanting to die & 0.685 & 0.086 & -0.045 & 0.051 \\
\hline 26 & No interest in anything & 0.523 & -0.227 & 0.178 & 0.452 \\
\hline 27 & Declining memory & 0.235 & 0.141 & 0.217 & 0.172 \\
\hline 28 & Lack of patience & 0.339 & -0.160 & 0.284 & 0.354 \\
\hline 29 & Lack of judgment & -0.151 & -0.008 & 0.090 & 0.833 \\
\hline 30 & Too dependent on others & 0.080 & 0.143 & -0.097 & 0.567 \\
\hline 31 & Distressed by blushing & -0.156 & 0.516 & 0.069 & -0.029 \\
\hline 32 & Stuttering, faltering voice & 0.128 & 0.309 & 0.270 & 0.083 \\
\hline 33 & Feel hot and cold & -0.357 & 0.377 & 0.660 & 0.004 \\
\hline 34 & Concern about urination or sexual organs & 0.352 & 0.404 & 0.107 & -0.294 \\
\hline 36 & Uneasy without reason & 0.194 & 0.225 & 0.028 & 0.437 \\
\hline 37 & Feel uneasy when alone & -0.046 & 0.336 & 0.026 & 0.250 \\
\hline 38 & Lack of confidence & 0.007 & 0.029 & 0.155 & 0.753 \\
\hline 39 & Irresolute about anything & -0.119 & 0.114 & -0.063 & 0.837 \\
\hline 40 & Easily feel misunderstood & 0.450 & 0.449 & -0.079 & -0.104 \\
\hline 41 & Lack faith in others & 0.560 & 0.036 & 0.063 & 0.141 \\
\hline 42 & Over-suspicious & 0.047 & 0.411 & 0.007 & 0.265 \\
\hline 43 & Unwilling to associate with others & 0.644 & -0.162 & 0.038 & 0.185 \\
\hline 44 & Feel self-abased & 0.222 & 0.280 & -0.001 & 0.384 \\
\hline 45 & Catastrophizing & 0.005 & 0.521 & 0.032 & 0.207 \\
\hline 46 & Physically exhausted & 0.172 & -0.191 & 0.656 & 0.238 \\
\hline 47 & In cold sweat when I hurry & -0.225 & 0.460 & 0.157 & 0.114 \\
\hline
\end{tabular}


Table 1 Factor loadings in the exploratory factor analysis of the university personality inventory (Continued)

\begin{tabular}{|c|c|c|c|c|c|}
\hline \multicolumn{2}{|l|}{ Item } & \multirow{2}{*}{$\begin{array}{l}\text { Factor } 1 \\
0.045\end{array}$} & \multirow{2}{*}{$\begin{array}{l}\text { Factor } 2 \\
0.031\end{array}$} & \multirow{2}{*}{$\frac{\text { Factor } 3}{0.745}$} & \multirow{2}{*}{$\frac{\text { Factor } \mathbf{4}}{-0.215}$} \\
\hline 48 & Dizzy when I stand up & & & & \\
\hline 49 & Have ever lost consciousness, cramp & 0.155 & 0.309 & 0.190 & -0.283 \\
\hline 51 & Over-rigid & 0.167 & 0.365 & -0.039 & 0.060 \\
\hline 52 & Cannot give up repeating things & -0.055 & 0.506 & -0.154 & 0.254 \\
\hline 53 & Susceptible to dirtiness & 0.052 & 0.417 & 0.154 & -0.034 \\
\hline 54 & Cannot get rid of meaningless idea & 0.272 & 0.382 & -0.085 & 0.286 \\
\hline 55 & Sense weird smell from myself & 0.151 & 0.551 & -0.059 & 0.029 \\
\hline 56 & Suspect others say something bad about me & 0.434 & 0.538 & 0.158 & -0.367 \\
\hline 57 & Wary of others & 0.214 & 0.600 & -0.202 & 0.325 \\
\hline 58 & Care about others' gaze & 0.087 & 0.638 & -0.101 & 0.268 \\
\hline 59 & Feel others despise me & 0.341 & 0.217 & 0.201 & 0.145 \\
\hline \multirow[t]{6}{*}{60} & Sensitive emotions & 0.432 & 0.401 & -0.115 & 0.104 \\
\hline & Interfactor correlations & & & & \\
\hline & Factor 1 & 1.000 & & & \\
\hline & Factor 2 & 0.567 & 1.000 & & \\
\hline & Factor 3 & 0.567 & 0.567 & 1.000 & \\
\hline & Factor 4 & 0.616 & 0.533 & 0.464 & 1.000 \\
\hline
\end{tabular}

The loadings of 0.50 or above are boldfaced

physical health [5]. Although mental illness is prevalent in university students $[6,7]$, a nonnegligible number of students are reluctant to use mental health services [8] and do not receive adequate treatment [9]. Previous studies have shown that mental health in university students could affect not only their grades but also their intention to drop out $[4,10]$. Given the relationship between academic outcomes and mental health, screening for and treating mental health problems have been proposed to promote mental health in university settings.

The University Personality Inventory (UPI), which was developed to assess the mental health status of university students in 1966, has been widely adopted in universities in Japan [11]. The UPI is a 60-item self-report questionnaire that uses a binary scale. The existing literature supports the reliability and convergent validity of this scale [12-14]. Students with a UPI total sum score above 20 or those who respond "yes" to item 25 ("Have an idea of wanting to die") are identified and guided to arrange personal interviews with mental health professionals [11]. However, mental health problems are heterogeneous and are expressed as a combination of emotional, physical, and social complaints [15]. Traditionally, the UPI has been regarded as a multidimensional instrument for assessing symptoms across four or five domains: physical symptoms, depression, anxiety, neuroticism, persecutory beliefs, and obsessive-compulsive symptoms [11]. However, it has been half a century since the UPI was developed in Japan. Differences in social norms and the degree of westernization could cause psychological distress specific to modern life [16] and affect the factor structure of an instrument that assesses the mental health status of Japanese university students. Furthermore, there have been limited reports on the factor structure of the UPI based on a statistical test for binary indicators [11, 17]. Although a recent report from China found a new five-factor structure consisting of physical symptoms, cognitive symptoms, emotional vulnerability, social avoidance, and interpersonal sensitivity [17], social differences make it difficult to extrapolate the mental health status of Japanese students from the results of a Chinese sample. In addition, the 60item measurement tool might be lengthy and onerous despite the UPI scale's established reliability. Brief measurement devices can alleviate respondent burden and lower refusal rates in surveys. It is thus necessary to assess the factor structure of the UPI and suggest the brief version for use among Japanese university students.

This study focuses on medical students, who experience a stressful environment characterized by an increasing study load due to the demanding medical curriculum [18]. In Japan, increasing numbers of students are dropping out of medical school, which is an important issue [19]. A systematic review concerning mental health among medical students indicated that their levels of psychological distress are consistently higher than in the general population [20]. The objective of this study was to assess the factor structure of the UPI in first-year medical students in Japan. To our knowledge, this study is the first to examine the factor structure of the UPI based on a statistical test for binary indicators of the scale. 
Table 2 Factor loadings for new four-factor model in the confirmatory factor analysis of the university personality inventory

\begin{tabular}{|c|c|c|c|c|c|}
\hline \multirow[t]{2}{*}{ Item } & & \multicolumn{4}{|c|}{ New four-factor model } \\
\hline & & Factor 1 & Factor 2 & Factor 3 & Factor 4 \\
\hline 6 & Full of dissatisfaction and complaints & 0.585 & & & \\
\hline 8 & My past and family is misfortune & 0.353 & & & \\
\hline 10 & Do not like meeting others & 0.617 & & & \\
\hline 23 & Restless & 0.581 & & & \\
\hline 24 & Irritable & 0.565 & & & \\
\hline 25 & Have idea of wanting to die & 0.523 & & & \\
\hline 26 & No interest in anything & 0.552 & & & \\
\hline 41 & Lack faith in others & 0.613 & & & \\
\hline 43 & Unwilling to associate with others & 0.553 & & & \\
\hline 31 & Distressed by blushing & & 0.356 & & \\
\hline 45 & Catastrophizing & & 0.539 & & \\
\hline 52 & Cannot give up repeating things & & 0.458 & & \\
\hline 55 & Sense weird smell from myself & & 0.398 & & \\
\hline 56 & Suspect others say something bad about me & & 0.462 & & \\
\hline 57 & Wary of others & & 0.703 & & \\
\hline 58 & Care about others' gaze & & 0.644 & & \\
\hline 1 & Poor appetite & & & 0.527 & \\
\hline 2 & Feel sick, stomachache & & & 0.541 & \\
\hline 12 & Lack of enthusiasm and positivity & & & 0.724 & \\
\hline 17 & Headache & & & 0.519 & \\
\hline 18 & Ache in neck and shoulder & & & 0.424 & \\
\hline 19 & Chest pain or feel oppressed & & & 0.481 & \\
\hline 33 & Feel hot and cold & & & 0.457 & \\
\hline 46 & Physically exhausted & & & 0.728 & \\
\hline 48 & Dizzy when I stand up & & & 0.408 & \\
\hline 21 & Intolerance & & & & 0.584 \\
\hline 29 & Lack of judgment & & & & 0.629 \\
\hline 30 & Too dependent on others & & & & 0.585 \\
\hline 38 & Lack of confidence & & & & 0.774 \\
\hline \multirow[t]{6}{*}{39} & Irresolute about anything & & & & 0.707 \\
\hline & Interfactor correlations & & & & \\
\hline & Factor 1 & 1.000 & & & \\
\hline & Factor 2 & 0.683 & 1.000 & & \\
\hline & Factor 3 & 0.692 & 0.624 & 1.000 & \\
\hline & Factor 4 & 0.618 & 0.769 & 0.554 & 1.000 \\
\hline
\end{tabular}

The factor 1 was labelled the "Depression and Ittitability" factor The factor 2 was labelled the "Anxiety and Persecutory belief" factor The factor 3 was labelled the "Physical symptoms" factor

The factor 4 was labelled the "Dependence" factor

\section{Methods}

\section{Participants}

This study was conducted between April 2010 and April 2019. The surveys were distributed to 1188 medical students in April of their first year at Dokkyo Medical University School of Medicine. Of the 1188 distributed surveys, 1185 questionnaires (749 males and 436 females) were completed. The demographic data (age and sex) were obtained from a self-report questionnaire. The 1185 students were divided into two subgroups according to their year of university admission. Subgroup A ( $n=589 ; 372$ males and 217 females) consisted of 
Table 3 Factor loadings for traditional four-factor model in the confirmatory factor analysis of the university personality inventory

\begin{tabular}{|c|c|c|c|c|c|}
\hline \multirow[t]{2}{*}{ Item } & \multirow[t]{2}{*}{$m$} & \multicolumn{4}{|c|}{ Traditional four-factor model } \\
\hline & & Factor 1 & \multirow[t]{2}{*}{ Factor 2} & \multirow[t]{2}{*}{ Factor 3} & \multirow[t]{2}{*}{ Factor 4} \\
\hline 1 & Poor appetite & 0.544 & & & \\
\hline 2 & Feel sick, stomachache & \multicolumn{2}{|l|}{0.591} & & \\
\hline 3 & Easily have diarrhea or constipation & \multicolumn{2}{|l|}{0.412} & & \\
\hline 4 & Care about palpitation and pulse & \multicolumn{2}{|l|}{0.395} & & \\
\hline 16 & Frequent insomnia & \multicolumn{2}{|l|}{0.400} & & \\
\hline 17 & Headache & \multicolumn{2}{|l|}{0.506} & & \\
\hline 18 & Ache in neck and shoulder & \multicolumn{2}{|l|}{0.356} & & \\
\hline 19 & Chest pain or feel oppressed & \multicolumn{2}{|l|}{0.473} & & \\
\hline 31 & Distressed by blushing & \multicolumn{2}{|l|}{0.270} & & \\
\hline 32 & Stuttering, faltering voice & \multicolumn{2}{|l|}{0.465} & & \\
\hline 33 & Feel hot and cold & \multicolumn{2}{|l|}{0.490} & & \\
\hline 34 & Concern about urination or sexual organs & \multicolumn{2}{|l|}{0.354} & & \\
\hline 46 & Physically exhausted & \multicolumn{2}{|l|}{0.662} & & \\
\hline 47 & In cold sweat when I hurry & \multicolumn{2}{|l|}{0.358} & & \\
\hline 48 & Dizzy when I stand up & \multicolumn{2}{|l|}{0.432} & & \\
\hline 49 & Have ever lost consciousness, cramp & \multicolumn{2}{|l|}{0.102} & & \\
\hline 6 & Full of dissatisfaction and complaints & \multicolumn{2}{|r|}{0.573} & & \\
\hline 7 & High expectation from parents & & 0.253 & & \\
\hline 8 & My past and family is misfortune & & 0.217 & & \\
\hline 9 & Over-worry about my future & & 0.502 & & \\
\hline 10 & Do not like meeting others & & 0.519 & & \\
\hline 11 & Feel that I am not myself & & 0.490 & & \\
\hline 12 & Lack of enthusiasm and positivity & & 0.621 & & \\
\hline 13 & Pessimistic & & 0.674 & & \\
\hline 14 & Distracted & & 0.622 & & \\
\hline 15 & Over-uneven in emotion & & 0.563 & & \\
\hline 21 & Intolerance & & 0.521 & & \\
\hline 22 & Inclined to worry & & 0.579 & & \\
\hline 23 & Restless & & 0.568 & & \\
\hline 24 & Irritable & & 0.506 & & \\
\hline 25 & Have idea of wanting to die & & 0.408 & & \\
\hline 26 & No interest in anything & & 0.529 & & \\
\hline 27 & Declining memory & & 0.502 & & \\
\hline 28 & Lack of patience & & 0.546 & & \\
\hline 29 & Lack of judgment & & 0.505 & & \\
\hline 30 & Too dependent on others & & 0.469 & & \\
\hline 36 & Uneasy without reason & & & 0.564 & \\
\hline 37 & Feel uneasy when alone & & & 0.317 & \\
\hline 38 & Lack of confidence & & & 0.638 & \\
\hline 39 & Irresolute about anything & & & 0.525 & \\
\hline 40 & Easily feel misunderstood & & & 0.466 & \\
\hline 41 & Lack faith in others & & & 0.496 & \\
\hline 42 & Over-suspicious & & & 0.501 & \\
\hline
\end{tabular}


Table 3 Factor loadings for traditional four-factor model in the confirmatory factor analysis of the university personality inventory (Continued)

\begin{tabular}{|c|c|c|c|c|c|}
\hline \multirow[t]{2}{*}{ Item } & & \multicolumn{4}{|c|}{ Traditional four-factor model } \\
\hline & & Factor 1 & Factor 2 & Factor 3 & Factor 4 \\
\hline 43 & Unwilling to associate with others & & & 0.419 & \\
\hline 44 & Feel self-abased & & & 0.627 & \\
\hline 45 & Catastrophizing & & & 0.527 & \\
\hline 51 & Over-rigid & & & & 0.396 \\
\hline 52 & Cannot give up repeating things & & & & 0.394 \\
\hline 53 & Susceptible to dirtiness & & & & 0.351 \\
\hline 54 & Cannot get rid of meaningless idea & & & & 0.623 \\
\hline 55 & Sense weird smell from myself & & & & 0.429 \\
\hline 56 & Suspect others say something bad about me & & & & 0.416 \\
\hline 57 & Wary of others & & & & 0.697 \\
\hline 58 & Care about others' gaze & & & & 0.639 \\
\hline 59 & Feel others despise me & & & & 0.475 \\
\hline \multirow[t]{6}{*}{60} & Sensitive emotions & & & & 0.596 \\
\hline & Interfactor correlations & & & & \\
\hline & Factor 1 & 1.000 & & & \\
\hline & Factor 2 & 0.753 & 1.000 & & \\
\hline & Factor 3 & 0.712 & 0.959 & 1.000 & \\
\hline & Factor 4 & 0.690 & 0.897 & 0.939 & 1.000 \\
\hline
\end{tabular}

The factor 1 was labelled the "Physical symptoms" factor

The factor 2 was labelled the "Depression" factor

The factor 3 was labelled the "Anxiety" factor

The factor 4 was labelled the "Neuroticism and persecutory beliefs" factor

students who entered the university in an evennumbered year, and subgroup B $(n=596 ; 377$ males and 219 females) consisted of students who entered the university in an odd-numbered year.

\section{Measures}

The UPI is a 60-item self-report measure assessing whether an individual usually experienced the described symptom during the past year [11]. For each item, a score of 1 was given for "Yes", and 0 was given for "No". After excluding the lie scales (items 5, 20, 35, and 50), we analyzed the 56 items describing psychosomatic problems. Traditionally, the 56-item UPI is regarded as a multidimensional instrument with as many as four or five factors [11]. The higher the score, the poorer the mental and/or physical condition.

\section{Statistical analysis}

Based on tetrachoric correlation coefficients, an EFA for binary indicators was conducted with promax rotation to analyze the underlying structure of the UPI in subgroup A. Because previous studies showed interfactor correlations in the factor structure of the UPI, we used promax rotation, which allows the factors to be correlated. We determined the number of factors to retain based on eigenvalues, the scree test, and the interpretability of the factors; four factors were retained. Furthermore, confirmatory factor analysis (CFA) was conducted to verify the dimensions in subgroup B. Five practical fit indices were used to evaluate the model fit: the goodness of fit index (GFI), the adjusted goodness of fit index (AGFI), the root mean square error of approximation (RMSEA), and the comparative fit index (CFI). A GFI, AGFI and CFI close to 1 indicate a good fit. An RMSEA $<0.05$ indicates good fit. The data analysis was performed using $\mathrm{R}$ for Windows, Version 3.6.3 (The R Foundation for Statistical Computing, Vienna, Austria) [21].

\section{Results}

The mean ( \pm standard deviation) age of the study participants was $19.6 \pm 1.7$ years (subgroup A: $19.6 \pm 1.7$; subgroup B: $19.5 \pm 1.6$ ). The overall reliability of the scale was good (alpha $=0.97$ ). Corrected item-total correlations for individual items ranged from 0.37 (item 31, "Distressed by blushing") to 0.80 (item 13, "Pessimistic"). The EFA with categorical variables yielded four factors in subgroup A. Factors 1 through Factor 4 were tentatively labeled "Depression and Irritability", "Anxiety and Persecutory Belief", "Physical Symptoms", and "Dependence". These factors accounted for $48.9 \%$ of the variance. 
Table 4 Factor loadings for traditional five-factor model in the confirmatory factor analysis of the university personality inventory

\begin{tabular}{|c|c|c|c|c|c|c|}
\hline \multirow{2}{*}{ Item } & \multirow{3}{*}{ Poor appetite } & \multicolumn{5}{|c|}{ Traditional five-factor model } \\
\hline & & \multirow{2}{*}{$\begin{array}{l}\frac{\text { Tradition }}{\text { Factor } 1} \\
0.544\end{array}$} & \multirow[t]{2}{*}{ Factor 2} & \multirow[t]{2}{*}{ Factor 3} & \multirow[t]{2}{*}{ Factor 4} & \multirow[t]{2}{*}{ Factor 5} \\
\hline 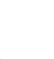 & & & & & & \\
\hline \multirow{2}{*}{2} & Feel sick, stomachache & 0.591 & & & & \\
\hline & Easily have diarrhea or constipation & 0.412 & & & & \\
\hline 4 & Care about palpitation and pulse & 0.395 & & & & \\
\hline 16 & Frequent insomnia & 0.400 & & & & \\
\hline 17 & Headache & 0.506 & & & & \\
\hline 18 & Ache in neck and shoulder & 0.356 & & & & \\
\hline 19 & Chest pain or feel oppressed & 0.473 & & & & \\
\hline 31 & Distressed by blushing & 0.270 & & & & \\
\hline 32 & Stuttering, faltering voice & 0.465 & & & & \\
\hline 33 & Feel hot and cold & 0.490 & & & & \\
\hline 34 & Concern about urination or sexual organs & 0.355 & & & & \\
\hline 46 & Physically exhausted & 0.662 & & & & \\
\hline 47 & In cold sweat when I hurry & 0.358 & & & & \\
\hline 48 & Dizzy when I stand up & 0.432 & & & & \\
\hline 49 & Have ever lost consciousness, cramp & 0.102 & & & & \\
\hline 6 & Full of dissatisfaction and complaints & & 0.573 & & & \\
\hline 7 & High expectation from parents & & 0.253 & & & \\
\hline 8 & My past and family is misfortune & & 0.217 & & & \\
\hline 9 & Over-worry about my future & & 0.502 & & & \\
\hline 10 & Do not like meeting others & & 0.519 & & & \\
\hline 11 & Feel that I am not myself & & 0.490 & & & \\
\hline 12 & Lack of enthusiasm and positivity & & 0.621 & & & \\
\hline 13 & Pessimistic & & 0.674 & & & \\
\hline 14 & Distracted & & 0.622 & & & \\
\hline 15 & Over-uneven in emotion & & 0.563 & & & \\
\hline 21 & Intolerance & & 0.521 & & & \\
\hline 22 & Inclined to worry & & 0.579 & & & \\
\hline 23 & Restless & & 0.568 & & & \\
\hline 24 & Irritable & & 0.506 & & & \\
\hline 25 & Have idea of wanting to die & & 0.408 & & & \\
\hline 26 & No interest in anything & & 0.529 & & & \\
\hline 27 & Declining memory & & 0.502 & & & \\
\hline 28 & Lack of patience & & 0.546 & & & \\
\hline 29 & Lack of judgment & & 0.505 & & & \\
\hline 30 & Too dependent on others & & 0.469 & & & \\
\hline 36 & Uneasy without reason & & & 0.564 & & \\
\hline 37 & Feel uneasy when alone & & & 0.317 & & \\
\hline 38 & Lack of confidence & & & 0.638 & & \\
\hline 39 & Irresolute about anything & & & 0.525 & & \\
\hline 40 & Easily feel misunderstood & & & 0.466 & & \\
\hline 41 & Lack faith in others & & & 0.496 & & \\
\hline 42 & Over-suspicious & & & 0.501 & & \\
\hline
\end{tabular}


Table 4 Factor loadings for traditional five-factor model in the confirmatory factor analysis of the university personality inventory (Continued)

\begin{tabular}{|c|c|c|c|c|c|c|}
\hline \multirow[t]{2}{*}{ Item } & & \multicolumn{5}{|c|}{ Traditional five-factor model } \\
\hline & & Factor 1 & Factor 2 & Factor 3 & Factor 4 & Factor 5 \\
\hline 43 & Unwilling to associate with others & & & 0.419 & & \\
\hline 44 & Feel self-abased & & & 0.627 & & \\
\hline 45 & Catastrophizing & & & 0.527 & & \\
\hline 51 & Over-rigid & & & & 0.452 & \\
\hline 52 & Cannot give up repeating things & & & & 0.447 & \\
\hline 53 & Susceptible to dirtiness & & & & 0.400 & \\
\hline 54 & Cannot get rid of meaningless idea & & & & 0.710 & \\
\hline 55 & Sense weird smell from myself & & & & & 0.436 \\
\hline 56 & Suspect others say something bad about me & & & & & 0.423 \\
\hline 57 & Wary of others & & & & & 0.709 \\
\hline 58 & Care about others' gaze & & & & & 0.650 \\
\hline 59 & Feel others despise me & & & & & 0.483 \\
\hline \multirow[t]{7}{*}{60} & Sensitive emotions & & & & & 0.607 \\
\hline & Interfactor correlations & & & & & \\
\hline & Factor 1 & 1.000 & & & & \\
\hline & Factor 2 & 0.753 & 1.000 & & & \\
\hline & Factor 3 & 0.712 & 0.959 & 1.000 & & \\
\hline & Factor 4 & 0.601 & 0.786 & 0.824 & 1.000 & \\
\hline & Factor 5 & 0.681 & 0.883 & 0.923 & 0.796 & 1.000 \\
\hline
\end{tabular}

The factor 1 was labelled the "Physical symptoms" factor

The factor 2 was labelled the "Depression" factor

The factor 3 was labelled the "Anxiety" factor

The factor 4 was labelled the "Obsessive-compulsive" factor

The factor 5 was labelled the "Persecutory beliefs" factor

Table 1 presents the rotated factor loadings for the new four-factor model. Twenty-six items had low loadings: 3, $4,7,9,11,13,14,15,16,22,27,28,32,34,36,37,40$, $42,44,47,49,51,53,54,59$ and 60.

After excluding the 26 items with low loadings, a CFA was conducted on the new four-factor model with the remaining 30 items in subgroup B. The factor loadings for the new four-factor model are shown in Table 2. The alpha coefficients for the four new factors were 0.91 for "Depression and Irritability", 0.83 for "Anxiety and Persecutory Belief", 0.89 for "Physical Symptoms" and 0.90 for "Dependence". Intercorrelations between the four factors in the new four-factor model ranged from 0.55 to 0.77. For the traditional four-factor model, CFA was conducted on the 56 items in subgroup B. The factor loadings for the traditional four-factor model are shown in Table 3. The alpha coefficients for the traditional four factors were 0.89 for "Physical Symptoms", 0.94 for "Depression", 0.90 for "Anxiety" and 0.89 for "Neuroticism and Persecutory Beliefs". Intercorrelations between the four factors in the traditional four-factor model ranged from 0.69 to 0.96 . For the traditional five-factor model, CFA was conducted on the 56 items in subgroup B. The factor loadings for the traditional five-factor model are shown in Table 4. The alpha coefficients for the traditional five factors were 0.89 for "Physical Symptoms", 0.94 for "Depression", 0.90 for "Anxiety", 0.78 for "Obsessive-compulsive" and 0.87 for "Persecutory Beliefs". Intercorrelations between the five factors in the traditional five-factor model ranged from 0.60 to 0.96 . Table 5 shows the fit indices for the CFA models.

\section{Discussion}

The aim of the present study was to examine the factor structure of the UPI among Japanese medical students. In our sample, the good internal consistency of the

Table 5 Fit indices for confirmatory factor models

\begin{tabular}{lllll}
\hline & GFI & AGFI & RMSEA & CFI \\
\hline One factor model & 0.999 & 0.999 & 0.034 & 0.976 \\
New four-factor model & 1.000 & 1.000 & 0.034 & 0.980 \\
Traditional four-factor model & 0.997 & 0.996 & 0.027 & 0.985 \\
Traditional five-factor model & 0.997 & 0.996 & 0.027 & 0.985 \\
\hline GFI goodness of fit index, AGFI adjusted goodness of fit index, RMSEA root \\
mean square error of approximatin, CFI comparative fit index
\end{tabular}


overall UPI (alpha $=0.97)$ indicated that a total score of this scale can be used as a global indicator of psychological distress. In subgroup $\mathrm{A}$, we demonstrated that the UPI consists of four factors via EFA with categorical variables. These factors, accounting for $48.9 \%$ of the variance, were labeled "Depression and Irritability", "Anxiety and Persecutory Belief", "Physical Symptoms", and "Dependence". Furthermore, the new four-factor structure showed good fit, and traditional factor structures previously reported were replicated by CFA in subgroup B.

With regard to the EFA, a previous study based on a statistical test for binary indicators found a new fivefactor structure in Chinese students [17]. The factors "Physical Symptoms" and "Cognitive Symptoms" in that study are comparable to the factors that we labeled "Physical Symptoms" and "Dependence", respectively. However, the UPI items belonging to the "Depression and Irritability" and "Anxiety and Persecutory Belief" factors in our new four-factor model constitute different factors in the Chinese study. The different response patterns between Japanese and Chinese individuals may be due to ethnicity or the social environment. In addition, the premorbid personality of so-called "Shin-gata utsubyo" [new-type depression (NTD)] might affect our results. In Japan, depression characterized by a premorbid personality different from the traditional melancholic temperament has been reported among young adults since approximately 2000 [22]. Initially, Tarumi called this novel depression "dysthymic-type" and advocated that the premorbid personality and symptomatologic features of NTD include avoidant narcissistic personality, extrapunitive feelings, and stress related to social rules and expectations [22, 23]. The "Depression and Irritability" and "Anxiety and Persecutory Belief" factors might be premorbid features of NTD reflecting extrapunitive feelings and stress related to social rules and expectations. Furthermore, avoidant narcissistic personality might also contribute to the "Dependence" factor. In Japanese students, subclinical symptoms of depression and anxiety could be accompanied by anger, avoidance, or dependence.

In psychological evaluation, somatic symptoms are generally considered manifestations of underlying psychological distress, such as anxiety or depression $[11,15]$. Previous studies found via EFA that items of emotional and physical symptoms merged and constituted new factors in Asian or Asian-American populations [15, 24-26]. However, exploratory analysis of the UPI did not show such merging of emotional and physical symptoms in either Japanese or Chinese students [17]. Discrepant responses between the UPI and other psychological measures might be explained by differences in participants' age. Because most studies employing the UPI focus on university students, participants in such studies are typically in their late teens or early 20s [11, 17]. Another explanation is that differences in items or expressed statements could affect the results.

The good fit of the CFA models of the UPI (Table 5) supports the use of all the models suggested in our study as indicators for psychological distress. However, both four-factor and five-factor traditional models of the UPI showed high interfactor correlations $(>0.95)$ between "Depression" and "Anxiety" in. In the same models, anxiety was also highly correlated with "Neuroticism and Persecutory Beliefs" (0.94) or "Persecutory Beliefs" (0.92). Although the structures of the abovementioned factors might have been distinct in Japanese students in the 1960s, they are not in students in the twenty-first century.

\section{Limitations}

The current study has some limitations. First, subject recruitment was restricted to medical students. Medical students are known to be at high risk for depression and suicidal ideation [27, 28]. In addition, students' university major could affect the response pattern on the UPI [11]. We cannot generalize our findings to all university students. Second, due to the lack of data on clinical diagnoses or other psychological measures, we could not confirm the criterion validity of the UPI. These limitations should be addressed in future studies. Third, this research was conducted over a long 9-year period, and some underlying psychosocial factors may change over time.

\section{Conclusion}

This study found a four-factor structure of the UPI by EFA in Japanese medical students. In Japan, this is the first study on the factor structure of the UPI based on a statistical test for binary indicators. Furthermore, CFA confirmed that the new four-factor structure as well as traditional factor structures previously reported showed good fit. The good internal consistency of the overall UPI (alpha $=0.97$ ) indicated that a total score of this scale can be used as a global indicator of psychological distress. The UPI is a valid and reliable measure that can be used to assess symptoms in multiple dimensions of mental health in university settings. The new four-factor model of the UPI consisting of 30 items is feasible and adequate psychological measure for modern university students. These findings offer a starting point for the detection of individuals with mental health problems. Future studies with a longitudinal design are needed to investigate the predictive validity of the UPI for mental or academic outcomes in university students.

\section{Abbreviations}

AGFl: Adjusted Goodness of Fit Index; CFA: Confirmatory Factor Analysis;

CFI: Comparative Fit Index; EFA: Exploratory Factor Analysis; GFI: Goodness of Fit Index; NTD: New-Type Depression; RMSEA: Root Mean Square Error of Approximation; UPI: University Personality Inventory 


\section{Acknowledgments}

The authors would like to thank all of the coworkers for their skillful contributions to the data collection and management.

\section{Authors' contributions}

NS conceived, and designed, and conducted the study, with the help of MS. NYF and KS contributed to designing methodology. All authors discussed the data and results and critically revised the manuscript. The authors approved the final version of the manuscript.

\section{Funding}

The authors received no specific funding for this work.

\section{Availability of data and materials}

All data used and/or analyzed during this study are not publicly available to maintain the anonymity of the individuals concerned. The dataset supporting the conclusions is available from the corresponding author on reasonable request.

\section{Ethics approval and consent to participate}

This protocol received approval from the Ethics Committee of Dokkyo Medical University School of Medicine (Approval number: 2019-015), and it conformed to the provisions of the Declaration of Helsinki. The requirement for written informed consent was waived by the Ethics Committee since the study involved record review only. Participants were given the opportunity to opt out of participation.

\section{Consent for publication}

The requirement for written informed consent was waived by the Ethics Committee, since the study involved record review only. Participants were given the opportunity to opt out of participation.

\section{Competing interests}

The authors report no conflicts of interest in this work.

Received: 21 May 2020 Accepted: 17 September 2020

Published online: 01 October 2020

\section{References}

1. Ishikawa H, Tachimori H, Takeshima T, Umeda M, Miyamoto K, Shimoda H, et al. Prevalence, treatment, and the correlates of common mental disorders in the mid 2010's in Japan: the results of the world mental health Japan 2nd survey. J Affect Disord. 2018;241:554-62. https://doi.org/10.1016/j.jad. 2018.08.050

2. Ministry of Education, Culture, Sports, Science and Technology, Government of Japan. School Basic Survey. (in Japanese). Available from URL: https:// www.mext.go.jp/b_menu/toukei/chousa01/kihon/1267995.htm. [Accessed 7 Apr 2020].

3. Japan Student Services Organization. Survey of Student Life 2016 (in Japanese). Available from URL: https://www.jasso.go.jp/about/statistics/ gakusei_chosa/2016.html. [Accessed 11 Apr 2020].

4. Stewart-Brown S, Evans J, Patterson J, Petersen S, Doll H, Balding J, et al. The health of students in institutes of higher education: an important and neglected public health problem? J Public Health Med. 2000;22(4):492-9. https://doi.org/10.1093/pubmed/22.4.492.

5. Roberts LW, Warner TD, Lyketsos C, Frank E, Ganzini L, Carter D. Collaborative research group on medical student health. Perceptions of academic vulnerability associated with personal illness: a study of 1,027 students at nine medical schools. Compr Psychiatry. 2001;42(1):1-15. https:// doi.org/10.1053/comp.2001.19747.

6. Storrie K, Ahern K, Tuckett A. A systematic review: students with mental health problems--a growing problem. Int J Nurs Pract. 2010;16(1):1-6. https://doi.org/10.1111/j.1440-172X.2009.01813.x.

7. Eisenberg D, Hunt J, Speer N. Mental health in American colleges and universities: variation across student subgroups and across campuses. J Nerv Ment Dis. 2013;201(1): 60-7. https//doi.org/10.1097/NMD.0b013e31827ab077.

8. Sasaki M. Barriers to use of mental health services by Japanese university students. Psychol Rep. 2007;100(2):400-6. https://doi.org/10.2466/pro.100.2.400-406.

9. Zivin K, Eisenberg D, Gollust SE, Golberstein E. Persistence of mental health problems and needs in a college student population. J Affect Disord. 2009; 117(3):180-5. https://doi.org/10.1016/j.jad.2009.01.001.
10. Pritchard ME, Wilson GS. Using emotional and social factors to predict student success. J Coll Stud Dev. 2003;44(1):18-28. https://doi.org/10.1353/ csd.2003.0008

11. Hirayama K, Japanese Association for College Mental Health. User guide for the UPI. [In Japanese] Tokyo: Sozo-shuppan; 2011.

12. Hosokawa R. University personality inventory (UPI) survey report. In: Proceedings of the Sanyo-Onoda City University, vol. 2; 2019. p. 89-99. [In Japanese].

13. Hattori I, Fujii C, Fukuzawa A. Survey regarding mental health conditions of high school students and attitudes of students and their teachers toward students' mental health issues. Seishin Shinkeigaku Zasshi. 2013;115(8):83146 [In Japanese].

14. Furuhashi Y. A study on the mental health of Japanese university students by the university personality inventory. A Epidemiol Public Health. 2020;3(1):1013.

15. Sugawara N, Yasui-Furukori N, Takahashi I, Matsuzaka M, Nakaji S. Age and gender differences in the factor structure of the Center for Epidemiological Studies Depression Scale among Japanese working individuals. Compr Psychiatry. 2015;56:272-8. https://doi.org/10.1016/j.comppsych.2014.09.004.

16. Chmitorz A, Kurth K, Mey LK, Wenzel M, Lieb K, Tüscher O, et al. Assessment of microstressors in adults: questionnaire development and ecological validation of the Mainz inventory of microstressors. JMIR Ment Health. 2020; 7(2):e14566. https://doi.org/10.2196/14566

17. Zhang J, Lanza S, Zhang M, Su B. Structure of the university personality inventory for chinese college students. Psychol Rep. 2015;1 16(3):821-39. https://doi.org/10.2466/08.02.PRO.116k26w3.

18. Slavin SJ. Medical student mental health: culture, environment, and the need for change. JAMA. 2016;316(21):2195-6. https://doi.org/10.1001/jama. 2016.16396.

19. Association of Japanese Medical colleges (AJMC). Survey on academic perfoemance of medical studetns. (in Japanese). Available from URL: https:// www.ajmc.jp/pdf/180305_2.pdf. [Accessed 9 Jul 2020].

20. Dyrbye LN, Thomas MR, Shanafelt TD. Systematic review of depression, anxiety, and other indicators of psychological distress among U.S. and Canadian medical students. Acad Med. 2006;81(4):354-73. https://doi.org/10 1097/00001888-200604000-00009

21. Venables WN, Smith DM, The R Core Team, 2020. An introduction to R, Notes on R: A Programming Environment for Data Analysis and Graphics Version 3.6.3.

22. Kato TA, Katsuki R, Kubo H, Shimokawa N, Sato-Kasai M, Hayakawa K, et al. Development and validation of the 22-item Tarumi's modern-type depression trait scale: avoidance of social roles, complaint, and low selfesteem (TACS-22). Psychiatry Clin Neurosci. 2019;73(8):448-57. https://doi. org/10.1111/pcn. 12842.

23. Tarumi S, Kanba S. Sociocultural approach toward depression: dysthymictype depression. (in Japanese) JPN bull. Soc Psychiatry. 2005;13:129-36.

24. Lee SW, Stewart SM, Byrne BM, Wong JP, Ho SY, Lee PW, et al. Factor structure of the Center for Epidemiological Studies Depression Scale in Hong Kong adolescents. J Pers Assess. 2008;90(2):175-84. https://doi.org/10. 1080/00223890701845385.

25. Yen S, Robins CJ, Lin N. A cross-cultural comparison of depressive symptom manifestation: China and the United States. J Consult Clin Psychol. 2000; 68(6):993-9. https://doi.org/10.1037//0022-006x.68.6.993.

26. Wang M, Armour C, Wu Y, Ren F, Zhu X, Yao S. Factor structure of the CES-D and measurement invariance across gender in mainland Chinese adolescents. J Clin Psychol. 2013;69(9):966-79. https://doi.org/10.1002/jclp.21978.

27. Rotenstein LS, Ramos MA, Torre M, Segal JB, Peluso MJ, Guille C, et al. Prevalence of depression, depressive symptoms, and suicidal ideation among medical students: a systematic review and meta-analysis. JAMA. 2016:316(21):2214-36. https://doi.org/10.1001/jama.2016.17324. J J

28. Maser B, Danilewitz M, Guérin E, Findlay L, Frank E. Medical student psychological distress and mental illness relative to the general population: a Canadian cross-sectional survey. Acad Med. 2019;94(11):1781-91. https:// doi.org/10.1097/ACM.0000000000002958.

\section{Publisher's Note}

Springer Nature remains neutral with regard to jurisdictional claims in published maps and institutional affiliations. 